\title{
An Investigation of Psychological Adjustment Differences among Chinese College Students: From the Perspectives of Their Gender, Major and Grade
}

\author{
Qiang Wang1*, Qian Zhang1,2*\# \\ ${ }^{1}$ School of Applied Technology, Southwest University, Chongqing, China \\ ${ }^{2}$ Research Center of Mental Health Education, Department of Psychology, Southwest University, \\ Chongqing, China \\ Email: "zhq@swu.edu.cn, 56798721@qq.com
}

Received 4 November 2015; accepted 26 December 2015; published 29 December 2015

Copyright (C) 2015 by authors and Scientific Research Publishing Inc.

This work is licensed under the Creative Commons Attribution International License (CC BY). http://creativecommons.org/licenses/by/4.0/

c) (i) Open Access

\begin{abstract}
The goal of the study was to examine levels of psychological adjustment among college students in China; 650 college students took part in Adolescents' Adaptability Scale (AAS). The results indicated that: 1) there was no significant gender difference in levels of psychological adjustment among college students in China; 2) there were apparent differences in majors. Students who specialized in physical art have the strongest levels of adjustment, while students who majored in arts have the weakest levels of adjustment; 3) significant differences were also existed in Grades, sophomores got the highest levels of adjustment, whereas seniors got the weakest levels of adjustment.
\end{abstract}

\section{Keywords}

College Students, Psychological Adjustment, Major, Gender, Grade

\section{Introduction}

Psychological adjustment was a type of mental disorders which existed in some college students in China (Zhang \& Zhang, 2007). If someone had serious adjustment problems when entering in college, he or she might

\footnotetext{
${ }^{*}$ Both Qian Zhang and Qiang Wang were the first authors because of their equal contribution to this article.

"Corresponding author.
} 
do extreme things in campus (e.g., suicide, aggression, inferiority, autism). Thus, problems of adjustment will do harm to students' quality of daily life and mental health.

Previous domestic researches correspondently showed that some serious issues of psychological adjustment existed in college students, such as social adjustment, learning adjustment, interpersonal adjustment and so on (Liu \& Guo, 2010; Song, Yang, \& Chi, 2010; Yang, 1998). Meanwhile, foreign researchers specified that psychological adjustment was a huge mental disorder among college students especially for freshman who entered into college (Klima \& Repetti, 2008; Priore, Mchugh, Picton, \& Haldane, 2004; Prinstein, Rancourt, Guerry, \& Browne, 2009; Sabatelli \& Anderson, 1991; Wan, Huan, Yeo, \& Ang, 2006). Additionally, psychological adjustment was closely connected with aggression among adolescence (Ano \& Vasconcelles, 2005; Crick \& Grotpeter, 1995). However, some issues exist in theoretical and empirical researches concerning adjustment research among Chinese college students: first, the narrow scope of study fans out from point to area. Some studies focused on special adjustment illness among patients. Secondly, few empirical studies have been conducted right now. Most of the studies have not carried out a systematic study of the adaptive development of college students. Based on this, adjustment can be measured according to prior work (Zhang \& Jiang, 2006; Zhang \& Zhang, 2007), the present study attempts to investigate adjustment situation among college students in gender, major and grade differences, so as to provide references for college students' adjustment education.

\section{Method}

\subsection{Participants}

The research participants of this study are 650 college students. Students from rural sources were 250, students from small towns were 200, and students from big cities were 200 (the non-social demographic data were excluded from the actual statistical data). Males were 325, and females were 325 . The freshmen were 160, the sophomores were 160, the junior were 150, and the senior were 180 .

\subsection{Measures}

Adolescents' Adaptability Scale (AAS) was used to measure adjustment of college students. The students are divided into six dimensions: physiological adaptation, emotional adaptation, interpersonal adaptation, learning adaptation, social adaptation and life adaptation. Exploratory factor analysis showed that the 6 factors explain the adaptation of college students. The reliability coefficient of the total scale was 0.827 , and the internal consistency reliability of each factor was between 0.526 and 0.722 , which showed that the scale had good reliability. Through a number of research groups of experts on the scale of the problem and the factor of the fitting of the situation, it has good content validity. The scale of the scale was also obtained by the correlation analysis of the structure validity (Zhang \& Jiang, 2006).

\section{Procedures}

The investigator conducted the measurement program of each survey, the unified instruction language, the class as the unit to carry on the group survey. Windows XP Spss16.0 was used to analyze the data.

\section{Results}

\subsection{Gender Differences in Adjustment among College Students}

The gender differences of the students' adjustment of the college students were investigated by T test. From Table 1, there were no significant differences between male students and female students, but the scores of male students were significantly higher than those of girls in the physiological adaptation, learning adaptability and social adaptability. On the interpersonal adaptability factor, the score of the female students is higher than that of the male students.

\subsection{Major Differences in Adjustment among College Students}

A single factor analysis of variance was used to investigate the differences among the major types of College Students' adaptability, and to compare the differences between the three types of LSD. Table 2 shows that there 
are significant differences between the major types of the overall adaptability and the main dimensions. The differences between the 3 major types are shown by the change of body art and science. The changes of the factors of all factors are basically the same.

\subsection{Grade Differences in Adjustment among College Students}

A single factor analysis of variance was used to investigate the differences of the students' Adaptability of the factors, and the difference between the four grades was analyzed by LSD. Table 3 showed that on the whole, the adaptability of college students exists significant differences in grade, the four trends were: Sophomore > Freshman > Junior > Senior, multiple comparison indicated that the A and two have significant differences, and, have significant difference. Is the total score of the adaptability, second and third grade students, the general adaptability level was significantly higher than that of grade 1 and 4, presented the inverted " $U$ " shaped curve, in addition to the grade difference of dimensions of emotional adaptation, interpersonal adaptation dimension and the learning adaptability dimension is not obvious, the grade differences of physiological adaptation dimension, social adaptability dimensions and the dimensions of fit are very significant.

Table 1. Gender differences analysis of adjustment among college students.

\begin{tabular}{cccc}
\hline Variables & Male M (SD) & Female M (SD) & T value \\
\hline PA & $3.31(0.57)$ & $2.85(0.61)$ & $7.21^{* *}$ \\
EA & $333(0.58)$ & $3.15(0.57)$ & 0.56 \\
RA & $9.22(1.65)$ & $9.65(1.49)$ & $-8.77^{* *}$ \\
LA & $9.58(1.81)$ & $9.65(1.57)$ & $3.57^{* *}$ \\
SA & $7.25(1.41)$ & $6.79(1.31)$ & $4.21^{* *}$ \\
LA & $6.35(1.39)$ & $6.41(1.38)$ & 0.28 \\
Total & $6.58(0.79)$ & $6.31(0.79)$ & 1.25 \\
\hline
\end{tabular}

Note: PA = Physiological Adjustment; Emotional Adjustment = EA; Relational Adjustment (interpersonal adjustment) = RA; Learning Adjustment = LA; Social Adjustment = SA; Life Adjustment $=$ LA. $^{*}=\mathrm{P}<0.05 ;^{* * *}=\mathrm{P}<0.01$.

Table 2. Major differences in adjustment among college students.

\begin{tabular}{cccccc}
\hline Variables & Arts (a) M (SD) & Science (b) M (SD) & Music (c) M (SD) & F value (df = 2) & Post Hoc \\
\hline PA & $3.41(0.68)$ & $3.04(0.58)$ & $3.41(0.61)$ & $27.66^{* *}$ & $\mathrm{a}<\mathrm{b}^{* *}, \mathrm{a}<\mathrm{c}^{* *}, \mathrm{~b}<\mathrm{c}^{* *}$ \\
EA & $3.01(0.48)$ & $3.06(0.46)$ & $3.44(0.36)$ & $5.29^{* *}$ & $\mathrm{a}<\mathrm{b}^{* *}, \mathrm{a}_{<}<\mathrm{c}^{*}$ \\
RA & $9.23(1.71)$ & $9.14(1.59)$ & $9.89(1.43)$ & $14.02^{* *}$ & $\mathrm{a}<\mathrm{c}^{* *}$ \\
LA & $9.50(1.71)$ & $9.68(1.56)$ & $9.77(1.57)$ & $10.88^{*}$ & $\mathrm{a}<\mathrm{b}^{* *}, \mathrm{~b}>\mathrm{c}^{* *}$ \\
SA & $6.88(1.25)$ & $6.87(1.19)$ & $7.21(1.35)$ & $10.34^{* *}$ & $\mathrm{a}<\mathrm{c}^{* *}, \mathrm{~b}<\mathrm{c}^{* *}$ \\
LA & $6.33(1.36)$ & $6.49(1.41)$ & $6.47(1.46)$ & $9.29^{* *}$ & $\mathrm{a}<\mathrm{b}^{*}, \mathrm{a}<\mathrm{c}^{* *}, \mathrm{~b}<\mathrm{c}^{*}$ \\
Total & $6.33(0.82)$ & $6.33(0.85)$ & $6.57(0.65)$ & $14.06^{*}$ & $\mathrm{a}<\mathrm{b}^{* *}, \mathrm{a}<\mathrm{c}^{* *}, \mathrm{~b}<\mathrm{c}^{*}$ \\
\hline
\end{tabular}

Note: PA = Physiological Adjustment; Emotional Adjustment = EA; Relational Adjustment = RA; Learning Adjustment = LA; Social Adjustment = SA; Life Adjustment = LA. ${ }^{*}=\mathrm{P}<0.05 ;{ }^{* *}=\mathrm{P}<0.01$.

Table 3. Grade differences in adjustment among college students.

\begin{tabular}{ccccccc}
\hline Variables & $\begin{array}{c}\text { Freshman (1) } \\
\text { M (SD) }\end{array}$ & $\begin{array}{c}\text { Sophomore (2) } \\
\text { M (SD) }\end{array}$ & $\begin{array}{c}\text { Junior (3) } \\
\text { M (SD) }\end{array}$ & $\begin{array}{c}\text { Senior (4) } \\
\text { M (SD) }\end{array}$ & $\begin{array}{c}\text { F value } \\
(\mathrm{df}=3)\end{array}$ & Post Hoc \\
\hline PA & $2.66(0.75)$ & $3.43(0.25)$ & $3.74(0.45)$ & $3.42(0.39)$ & $5.43^{* *}$ & $1<2^{*}, 1<3^{* *}$ \\
EA & $3.43(0.52)$ & $3.75(0.85)$ & $3.89(0.34)$ & $2.69(0.34)$ & 3.05 & \\
RA & $9.25(1.65)$ & $9.47(1.64)$ & $9.25(1.87)$ & $9.24(1.56)$ & 1.62 & \\
LA & $9.57(1.71)$ & $9.87(1.62)$ & $9.64(1.84)$ & $9.44(1.54)$ & 3.41 & \\
SA & $7.21(1.35)$ & $7.33(1.25)$ & $6.78(1.16)$ & $6.28(1.43)$ & $6.57^{* *}$ & $1>3^{* *}, 1>4^{* *}, 2>3^{* *}, 2>4^{* *}, 3>4^{*}$ \\
LA & $6.43(1.31$ & $6.28(1.34)$ & $6.34(1.65)$ & $6.14(1.32)$ & $5.65^{* *}$ & $1<2^{* *}, 2>3^{* *}, 2>4^{*}$ \\
Total & $6.78(0.71)$ & $6.88(0.46)$ & $6.57(0.76)$ & $6.37(0.57)$ & $4.74^{* *}$ & $1<2^{* *}, 2>3^{*}, 2>4^{*}$ \\
\hline
\end{tabular}

Note: PA = Physiological Adjustment; Emotional Adjustment = EA; Relational Adjustment = RA; Learning Adjustment = LA; Social Adjustment = SA; Life Adjustment $=$ LA. ${ }^{*}=\mathrm{P}<0.05 ;^{* *}=\mathrm{P}<0.01$. 


\section{Discussion}

\subsection{Gender Differences in Adjustment among College Students}

The research shows that there is no significant difference between male and female college students, but the score of boys is significantly higher than that of female students in the physiological adaptability, learning adaptability and social adaptability factors. On the interpersonal adaptability factor, the score of the female students is higher than that of the male students. This is consistent with some of the results of the domestic research. Such as previous research indicated that girls than boys have adaptation problems, but there was no significant difference in (Zhao, 1999). In addition, other researches show that the adaptive ability of male and female students, the level of adaptability was not existing gender difference (Ma, 2002). Meanwhile, some studies demonstrated that learning adaptability of boys was significantly better in girls (Feng \& Li, 2002). But the results of this study were in discrepancy with the relevant conclusions. Such as students fitness levels exist significant gender differences, among boys rather than among girls (Tao, 2002); Chen Lemna minor study found that in a woman's life adaptation ability is stronger than boys (Qi, 2005). Therefore, this controversial issue is worthy of our in-depth study. There were two main reasons for the difference between the two sexes: one is the maturity of the students' body and mind. College students with physical maturity and psychological development, have the ability of independent learning, life and communication, in the process of socialization, male and female students in the adaptation process of self-confidence and success to get positive reinforcement, although the two in some adaptive quality of the points, such as boys in the physiological adaptability, learning adaptability and life adaptability, and girls in interpersonal adaptability than boys, but can smoothly adapt to college life. Two is the University's education atmosphere. The education mode of higher education and its environment atmosphere respect the gender equality of education, and lead to the formation and development of male and female students' adaptability. This shows that the results of our study on the adaptability of gender differences are in line with the actual situation of contemporary college students.

\subsection{Major Differences in Adjustment among College Students}

This study found that there is a significant difference between the students' adaptability to the major types, and the students' adaptability is the best. This is consistent with the results of prior research (Zhao, 1999). The possible reason is that, on the one hand, from the perspective of employment, it is the expectation of College Students' expectation of professional development project to the daily psychological and behavioral state, and ultimately affects the adaptability level. Reality shows that the body art (such as music, art, sports, etc.) and the arts and Sciences, compared with a wider employment space, and science class (such as mathematics, geography, chemistry, etc.) are better than the liberal arts. On the other hand, from the nature of the discipline, the liberal arts majors are more emphasis on the study of theoretical knowledge, while the body art is more focused on social practice, while the science majors in the two. Therefore, college students majored in liberal arts had better levels of adaptability than those specialized in science, but students who majored in science had better adaptability than those who majored in art.

\subsection{Grade Differences in Adjustment among College Students}

This study shows that there are significant differences in the overall adaptability of different grades of college students in the dimensions of their physical adaptation, social adaptation and life adaptability. The results of this study are not consistent with the results of previous researches (Ma, 2002; Stewart, Sokol, Healy, \& Chester, 1986; Tao, 2002). In particular, the differences of college students' adaptability were mainly manifested in two aspects: 1) the results of the overall adaptive development, the performance of Sophomore $>$ Freshman $>$ Junior $>$ Senior trend, showing a "U" type. Investigate its reason, it may be a specific period of College Students' growth experience and living environment has a great impact on their adaptability. The first semester of college students enrolled in the first term is a special stage of the convergence of high school and university, they have a new living environment and learning tasks have a process of adaptation, the environment, development goals, social status and role expectations and so on. Therefore, we should take active and effective measures to improve the adaptability of students. The students have been familiar with the environment, which is in the best condition. The four students have a great impact on the job market and social environment. The three students have a great impact on the market and social environment. Therefore, the employment pressure has become more and more 
obvious. 2) In the dimension of emotional adaptation, interpersonal adaptation and learning adaptability, there is no obvious grade difference, which indicates that the adaptability of the level has entered a relatively stable period. Grade difference was significant in physiological adaptation, social adaptability and life adaptability. The reason is that college students are in the peak period of physiological changes and the development of self consciousness (Blake, 1981; Crick \& Grotpeter, 1995; Denise, 1980; Huang \& Zheng, 1999). The adaptability of freshman's new life and learning environment and the big four of the employment pressure and the career choice will be temporarily adapted to the relative difficulty. This shows that the adaptability of college students in different grades is more likely to be influenced by life experiences and social environment, which can provide a theoretical basis for us to carry out the adaptive training of college students.

\section{Limitations, Future Research Directions, and Implications}

The study may be one of the first to explore the psychological adjustment of college students in China. The results, nevertheless, should be noticed in light of some limitations. First, the sample selected in the study was a relatively small and homogeneous group several colleges in Chongqing municipality of China. As a result, cautions should be made when the conclusions were generalized to another population (e.g. cross-cultures, nationality). Second, the data obtained from a cross-sectional design confine the final determination of casual relationships. Importantly, in future, longitudinal studies should be developed to provide pronounced evidence on the relationship among variables explored in the study, to scientifically and exactly classify levels of adjustment among college students. These results, from our points of view, could be used as a useful reference for implementing psychological adjustment education practice among college students in China.

\section{Conclusions}

1) There was no significant gender difference in levels of psychological adjustment among college students in China;

2) There were apparent differences in majors. Students who specialized in physical art have the strongest levels of adjustment, while students who majored in arts have the weakest levels of adjustment;

3) Significant differences were also existed in grades, sophomores got the highest levels of adjustment, while seniors got the weakest levels of adjustment.

\section{Acknowledgements}

The present study was supported by "the Fundamental Research Funds for the Central Universities" (Grant Number: SWU1309266) and was supported by the Grant of Social Science and Humanity Project from the Ministry of Education in China (Grant Number: 13YJC190030), also from the PhD funds of "the Fundamental Research Funds for the Central Universities" (Grant Number: SWU1509528), and was supported by "the Fundamental Research Funds for the Central Universities" (Grant Number: XDJK2016C077). We are indebted to each college student who participated in the study. We thank the anonymous reviewers for their kind feedback on previous drafts of this manuscript.

\section{References}

Ano, G. G., \& Vasconcelles, E. B. (2005). Religious Coping and Psychological Adjustment to Stress: A Meta-Analysis. Journal of Clinical Psychology, 61, 461-480. http://dx.doi.org/10.1002/jclp.20049

Blake, J. (1981). The Only Child in America: Prejudice versus Performance. Population and Development Review, 7, 43-54. http://dx.doi.org/10.2307/1972763

Crick, N. R., \& Grotpeter, J. K. (1995). Relational Aggression, Gender, and Social-Psychological Adjustment. Child Development, 66, 710-722. http://dx.doi.org/10.2307/1131945

Denise, F. P. (1980). The Only Child Grows Up: A Look at Some Characteristics of Adult Only Children. Family Relations, 29, 99-106. http://dx.doi.org/10.2307/583722

Feng, T. Y., \& Li, H. (2002). A Preliminary Study on Learning Adjustment among Contemporary College Students. Psychological Exploration, 22, 44-48.

Huang, X. T., \& Zheng, Y. (1999). Psychological Traits and Education among Contemporary College Students in China. Shanghai: Shanghai Education Publishing House, 22-24. 
Klima, T., \& Repetti, R. L. (2008). Children’s Peer Relations and Their Psychological Adjustment: Differences between Close Friendships and the Larger Peer Group. Merrill-Palmer Quarterly: Journal of Developmental Psychology, 54, 151-178. http://dx.doi.org/10.1353/mpq.2008.0016

Liu, L. Y., \& Guo, L. Z. (2010). Investigation and Study on the College Students' Ability of Social Adaptation. Journal of Dezhou University, 1, 96-98.

Ma, Y. (2002). The Relation between Psychological Adjustment and Neural Traits. Journal of Health Psychology, 10, 425-426.

Prinstein, M. J., Rancourt, D., Guerry, J. D., \& Browne, C. B. (2009). Peer Reputations and Psychological Adjustment. In K. H. Rubin, M. Bukowski, B. Laursen, et al. (Eds.), Handbook of Peer Interactions, Relationships, and Groups (pp. 548-567).

Priore, C. D., Mchugh, k., Picton, s., \& Haldane, E. (2004). Psychological Problems and Adjustment. Springer Berlin Heidelberg, 22, 325-332. http://dx.doi.org/10.1007/978-3-662-07841-9_45

Qi, L. G. (2005). Analysis on Psychological Adjustment among Freshmen. Journal of Northeast Normal University (Social Sciences Edition), 3, 157-161.

Sabatelli, R. M., \& Anderson, S. A. (1991). Family System Dynamics, Peer Relationships, and Adolescents’ Psychological Adjustment. Family Relations, 40, 363-369. http://dx.doi.org/10.2307/584891

Song, Z., Yang, X. L., \& Chi, L. J. (2010). A Discussion on the Cultivation of College Students' Social Adaptation. Journal of Tongren University, 12, 113-115.

Stewart, A. J., Sokol, M., Healy, J. M., \& Chester, N. L. (1986). Longitudinal Studies of Psychological Consequences of Life Changes in Children and Adults. Journal of Personality and Social Psychology, 50, 143-151. http://dx.doi.org/10.1037/0022-3514.50.1.143

Tao, S. (2002). On Adjustment Problems When Entry into Colleges from Life-Span Perspective. Journal of Beijing Normal University (Social Sciences Edition), 22, 81-87.

Wan, H. C., Huan, V. S., Yeo, L. S., \& Ang, R. P. (2006). Asian Adolescents’ Perceptions of Parent, Peer, and School Support and psychological Adjustment: The Mediating Role of Dispositional Optimism. Current Psychology, 25, 212-228. http://dx.doi.org/10.1007/s12144-006-1004-6

Yang, Z. J. (1998). A Social Psychology Analysis on Social Adjustment among College Students. Yunnan Higher Education Research, 4, 34-35.

Zhang, D. J., \& Jiang, Q. (2006).Adolescents’ Adaptability Scale (AAS). Psychological and Behavioral Research, 4, 81-84.

Zhang, D. J., \& Zhang, Q. (2007). Developmental Characteristics of Adaptability among College Students in China. Journal of Southwest University (Social Sciences Edition), 33, 124-128.

Zhao, F. C. (1999). A Study on the Problems of Psychological Adjustment among Freshmen. Journal of Health Psychology, 7, 397-399. 